\title{
APRESENTAÇÃO \\ DOSSIÊ SOCIALIDADES INTERESPECÍFICAS: OS OUTROS SÓCIOS DO HUMANO
}

\author{
Beto Vianna ${ }^{1}$ \\ Ugo Maia ${ }^{2}$
}

doi) $10.21665 / 2318-3888 . v 5 n 10 p 04-21$

\section{Introdução}

Em 2009, o ex-Beatle Paul McCartney lançou a campanha Meat-free monday (segundafeira sem carne), incentivando seus coespecíficos a serem vegetarianos uma vez por semana. Além da preocupação com a saúde planetária - uma "cosmopolítica", se podemos adaptar o termo de Isabelle Stengers (2010) para o showbiz -, a campanha é justificada como um passo rumo à diminuição do sofrimento animal. Em recente entrevista (BRADY, 2017), pergunta-se a Paul por que recomendar apenas um dia para a restrição alimentar, e não eight days a week, se a questão é, de fato, grave. Vegetariano em tempo integral, ele responde que não quer obrigar ninguém a adotar suas próprias convicções. "Temos que ser gentis com as pessoas", diz Paul. Em 1904, o cavalo Clever Hans era exibido na Alemanha resolvendo questões de aritmética e outras tarefas intelectuais (CANDLAND, 1993). A performance atraiu a atenção dos cientistas, e três anos depois, o psicólogo Oskar Pfungst, por meio de engenhosos experimentos, concluiu que Hans era capaz de detectar mudanças emocionais na audiência, iniciando ou

\footnotetext{
${ }^{1}$ Doutor em Estudos Linguísticos (UFMG). Professor do Departamento de Letras do Campus de Itabaiana da Universidade Federal de Sergipe (UFS) e professor-colaborador do Programa de Pós-graduação em Antropologia da mesma universidade. É um dos coordenadores do Grupo Inuma - interfaces humano e não humano (CNPq-UFS). E-mail: btvianna@gmail.com

${ }^{2}$ Doutor e Mestre em Antropologia pela Universidade de São Paulo. Professor do Departamento de Ciências Sociais e coordenador do Programa de Pós-Graduação em Antropologia da Universidade Federal de Sergipe. Coordena o Grupo Inuma - interfaces humano e não humano (CNPq-UFS). E-mail: ugomaia@ufs.br.
} 
completando seus movimentos indicativos da resposta. Em O relojoeiro cego, o zoólogo neodarwinista e divulgador da ciência Richard Dawkins ironiza o uso das classificações animais por especialistas de outras áreas:

Eu soube que há pouco um tribunal precisou decidir se as lagostas eram insetos ou "animais" (tratava-se de saber se era permissível cozinhá-las vivas). Zoologicamente falando, as lagostas certamente não são insetos. São animais, tanto quanto os insetos e os humanos. Não há razão para se exaltar sobre os modos como diferentes pessoas empregam as palavras, muito embora eu mesmo, em minha vida cotidiana, esteja pronto a me exaltar com gente que cozinha lagostas vivas (DAWKINS, 2001, p. 18).

Se há algo em comum nos três casos, é o estatuto ontológico rigorosamente instável dos novos sócios que, a convite ou contra a vontade do observador humano, imiscuem-se nos relatos. Não se sabe como Clever Hans entrava em sintonia com o fluxo emocional da audiência (um fenômeno que deveria causar mais assombro que qualquer façanha intelectual), mas a "farsa" descoberta pelo psicólogo fez desse cavalo um caso paradigmático nos estudos de cognição animal, lembrando-nos que é preciso evitar, a todo custo, que as expectativas humanas contaminem o comportamento observado. Hans é o equivalente equino do princípio da parcimônia (ou "cânon") de Lloyd Morgan, que diz que nunca devemos interpretar um ato como resultado de uma "faculdade psicológica mais elevada, se esse mesmo ato pode ser interpretado como resultado de uma faculdade que se situa mais abaixo na escala psíquica" (DE WAAL, 2001, 67). Dawkins, um advogado da ciência como instância privilegiada do conhecimento, recomenda paciência com os (maus) usos leigos da nomenclatura zoológica, mas é capaz de se indignar com a crueldade contra os animais (ainda que, para isso, tenha de se retirar para a "vida cotidiana"). Já o astro Paul McCartney mostra-se mais à vontade em meio à profusão de sócios que surgem em sua campanha de mudança de hábito: atento à suscetibilidade dos fãs, ao sofrimento animal, e, é claro, ao derretimento da calota polar. Não só humanos, e não só seres viventes, mas todo um clube repleto de não humanos, animados ou não, cada um reclamando sua parte na ação.

Dentre os atores não humanos, a irrupção dos animais nas preocupações das ciências sociais (e por extensão, humanas, ou mesmo as "humanidades", como se diz nos países anglófonos) nas últimas três ou quatro décadas, tem sido lembrada com insistência na 
literatura acadêmica (ver, por exemplo, a coletânea de Kalof e Fitzgerald, 2007). A ênfase é compreensível. A questão animal sempre esteve presente, mas nunca foi um tema confortável, ou incontroverso, no pensamento ocidental. Habituamo-nos, desde os gregos, a postular categorias de alma para justificar os modos que escolhemos lidar com a diversidade de corpos: quem (ou o que) é aceitável comercializar, escravizar, mutilar, amar. Foi preciso emergir a consciência global de uma catástrofe igualmente global - o chamado "antropoceno", em que a referência ao humano está longe de ser uma homenagem $^{3}$ - para começarmos a desconfiar que as relações que estabelecemos com nossos outros sócios precisa ser repensada drasticamente. A ciência e a filosofia modernas não foram, nesse caso, um divisor de águas. Ao contrário, desde a "mente primeira" de Locke, Descartes e Kant (RORTY, 1994), enredamo-nos em um vocabulário tortuoso sobre semelhanças e diferenças físicas, psíquicas e morais, que os recentes e multidisciplinares animal studies, cada um a seu modo, procuram ora elucidar (nem sempre com sucesso), ora ignorar (com resultados mais promissores).

É a partir das fronteiras transportas pela virada animal nas ciências do humano, e pela perspectiva mais ampla, e portanto mais inclusiva, das agências não humanas, que este dossiê Socialidades Interespecíficas foi pensado. Para a satisfação dos editores, seus cinco artigos componentes revelaram-se cinco caminhos distintos, mas igualmente interessantes, que nos convidam a percorrer velhas associações só recentemente notadas, ou, quem sabe, a estabelecer associações novas em folha.

\section{Socialidades}

O título do dossiê pede um esclarecimento. Socialidade (sociality) é conceito que Roy Wagner inventa e define como um "vir a ser" 4 e um conjunto de relações (1981, p. 91). Posteriormente foi retomado por Marilyn Strathern (1996), sendo por ela contraposto às antíteses indivíduo/sociedade e parte/todo tão caras à teoria social de base durkheimiana e que estão por trás da definição de sociabilidade. Nesse sentido, sociabilidade

\footnotetext{
3 STEFFEN et al, 2011.

4 "Sociality is a 'becoming', not a 'become'" (WAGNER, 1974, p. 112).
} 
(sociability) seria o modo como as conexões entre indivíduos (ou entre partes) são produzidas quando os consideramos a realidade concreta, modelo que ainda conserva a sociedade como um agregado paradigmático de indivíduos.

Sociabilidade concerne ao universo das relações inter-humanas e emerge como ferramenta explicativa das relações entre indivíduos humanos concretos membros de uma sociedade. Marylin Strathern pondera que "o problema com o conceito de 'sociedade' são os outros conceitos que este produz" (STRATHEN, op. cit., p. 52), em especial indivíduo, um dos principais desafios para a antropologia. Inversamente, socialidade concerne ao feixe de relações que é a pessoa (inconfundível, portanto, com o indivíduo), concluindo a autora que "se quisermos produzir teorias adequadas sobre a realidade social, então o primeiro passo é apreendermos as pessoas como, simultaneamente, possuindo potencial para relações e sempre incluídas numa matriz de relações com os outros" (STRATHEN, op. cit., p. 55). Com o recurso à socialidade, Marilyn Strathern e Roy Wagner afirmam a imanência das relações sociais à existência humana, sendo a pessoa (e não o indivíduo, átomo conectado a uma entidade exterior - a sociedade) uma potencialidade atualizada a partir de sua realidade relacional.

Em consequência, a componente determinante da pessoa é sua capacidade de gerar e conservar relações recíprocas (HAMLYN, 1984), de mão dupla, posto não ser ela uma entidade discreta anterior e diferente de sua matriz de relações com outras pessoas. E no limite, todo ente imerso em uma matriz de relações é potencialmente uma pessoa, uma vez que relação não é uma habilidade específica, mas uma condição imperativa à existência, seja existência para os humanos ou não. Tal fórmula parece se ajustar ao pensamento ameríndio quando este estende à natureza o protocolo da reciprocidade, código humano para identificar e domesticar relações, revelando que ali, na anta, no macaco, no mastro ritual, no arco-íris e nos espíritos auxiliares dos pajés (muitas vezes mestres de animais) há a pessoa, criando para nós, ocidentais modernos, uma série de dificuldades na preservação da antítese natureza/cultura. Todavia, embaralhar fronteiras do que seria, de um lado, a natureza, e do outro a cultura, não é façanha exclusivamente indígena e tal ação encontra-se também entre nós; a diferença está entre ser uma prática oficial ou não (LATOUR, 1994). 
O fundo comum é que natureza e cultura não são assimiláveis à oposição inato e adquirido (WAGNER, 1981), nem polos purificados (LATOUR, 1994), conforme se concebeu no Ocidente moderno. Os dois campos - em verdade, dois campos apenas a partir da vigência das antíteses acima e de outras congêneres - implicam-se mutuamente, sempre, seja na produção dos monstros híbridos latourianos ${ }^{5}$, seja por meio da evidência da natureza como espaço socializado, consoante as cosmologias amazônicas (DESCOLA, 1996).

Portanto, o alcance do divisor natureza/cultura no Ocidente deve ser relativamente considerado, compartilhando espaço com formas compósitas que a todo momento desestabilizam os polos natureza e cultura (LATOUR, 1994). Se o Ocidente não é tão moderno assim como se deseja é porque não realizou com pleno sucesso a transcendência da cultura sobre a natureza, permitindo brechas por onde emergem redutos híbridos e que, de resto, conhecemos desde a aflição pela sobrevivência de ideias e práticas bárbaras em pleno seio da civilizada Inglaterra vitoriana (FRAZER, 2005).

Considere-se, assim, o conjunto total das relações entre humanos e não humanos (ou extra-humanos, mais que humanos...) nas socialidades interespecíficas, relações que extrapolam, por óbvio, o domínio das interações entre entes "animados", conectando campos mais inclusivos, como aqueles relativos à vida orgânica (humanos, animais, plantas, fungos, vírus, bactérias etc.) e à existência não orgânica (artefatos, máquinas, pensamentos, palavras, deuses, espíritos, demiurgos). Ou, utilizando, velhas categorias próximas, relacionando entes "animados" e entes "inanimados". Como acontece com todas as velhas categorias - que moldam, fixam e congelam sentidos - os campos dos entes animados e dos entes inanimados são oponíveis entre si, pois replicantes do grande divisor natureza/cultura que opera no pensamento ocidental. Todavia, mesmo no terreno de hegemonia desse grande divisor há as brechas por onde emergem tão somente modos

5 “... embriões congelados, sistemas especialistas, máquinas digitais, robôs munidos de sensores, milho híbrido, bancos de dados, psicotrópicos liberados de forma controlada, baleias equipadas com rádiosondas, sintetizadores de genes, analisadores de audiência etc. (LATOUR, op. cit. p. 53). 
distintos de "vida", vida orgânica e vida não orgânica, iluminando as associações que fazem com que palavras rituais tenham plena capacidade de criar realidades; ou a intencionalidade atribuída a artefatos sagrados ou efêmeros, às vezes relés eletrodomésticos, como investiga o pioneiro - mas, infelizmente, pouco levado a sério, em meio aos anéis que retornam para seus donos, às moedas sacrificadas e aos carros magoados por terem sido vendidos - estudo de Lyall Watson (1990) sobre as afecções de "coisas" com as quais dividimos nosso cotidiano. ${ }^{6}$

\section{Não-humanidades não-animadas}

Os cinco artigos reunidos neste dossiê trazem, de maneiras diversas, preocupações em torno do grande divisor natureza/cultura, matriz de antíteses como sujeito/objeto, material/imaterial e animado/inanimado. Embora a maioria apresente etnografias ou tracem percursos das relações animais-humanos nas ciências humanas em geral, a chamada do dossiê atentou para a amplitude do tema das relações humanos-não humanos:

... reunir contribuições de pesquisas bibliográficas ou de natureza etnográfica a respeito das múltiplas formas que assumem as associações entre humanos e não humanos, seja no que concerne à relação com o animal (...) à relação com artefatos em contexto de coletivos não hegemônicos, como os ameríndios e afro-brasileiros; ou à composição de redes sociotécnicas modernas.

Assim, a Revista Ambivalências oferece sua contribuição ao debate em torno das discussões sobre as relações entre humanos e não humanos que vêm marcando forte presença em periódicos nacionais especializados, a maioria das áreas da antropologia e das ciências sociais. ${ }^{7}$

\footnotetext{
6 Note-se, por exemplo, os conceitos de pontes orgânicas, que sugere conexões entre matéria e pensamento, e de impressão digital emocional proposto pelo autor a fim de discutir as consequências da impressão que deixamos nas coisas a partir de nossa convivência com elas.

7 Foram uma dezena de dossiês sobre relações animais-humanos publicados em periódicos brasileiros das Ciências Sociais nos últimos seis anos: Anuário Antropológico, v. 2, UNB (2012); Anthropológicas, 24(1), UFPE (2013); Rau, 7(1), UFSCAR e CADECS, 3(1), UFES (2015); Vibrant, 13(2), ABA / Teoria \& Cultura, 11(2), UFJF / REIA, 1(2), UFPE / Iluminuras, 17(42), UFRGS (2016) / Vivência, 1(49), UFRN e Horizontes
} 
As reflexões globais a respeito da relação com o animal contam com volume fantástico, expressivo tanto em termos de extensão quanto de profundidade. No que concerne à extensão, o interesse pelas relações animais-humanos está presente em áreas como sociologia, zoologia, antropologia, filosofia, direito e medicina veterinária. No quesito profundidade, considerando-se o ano de produção do artigo, livro, ou dossiê - e não a sua complexidade - vemos que uma produção de estudos sobre o tema existe desde os anos de 1970, tornando-se gradativamente copiosa e produzindo o advento do animal turn dos anos de 1990. Logo, no domínio dos estudos das relações humanos-não humanos em geral as relações específicas animais-humanos assumem a dianteira no interesse despertado dentro e fora das universidades. Isso, por suposto, deve-se ao tipo de fascínio, apelo e sedução que os animais exercem sobre nós, pois sendo, simultaneamente, síntese e antítese humana, assumem a posição tanto de metáfora quanto de metonímia de nós mesmos. Todavia, se perguntamos pelo animal, se perguntamos "o que pode um animal?", a indagação é igualmente pertinente para o domínio do material: "o que pode uma coisa?".

É nesse sentido que o artigo de Luciana Novaes, intitulado "Breve imaginação antropológica sobre animação da escrita e animismo na ciência arqueológica", reivindica que os arqueólogos sejam afetados pelas situações de campo, trazendo à luz uma crítica à autoridade da escrita em arqueologia enquanto forma de manipulação e invenção de narrativas sobre o passado de coletivos de humanos e não humanos (em especial artefatos). Argumenta a autora que tal manipulação é parte das estratégias discursivas dos métodos clássicos da disciplina que, além de impedir que os arqueólogos sejam afetados pelas situações de campo, garantem-Ihes a univocidade da agência na produção do conhecimento arqueológico. A afecção, aliás, é o leitmotiv das reflexões a respeito de relações interespecíficas, porque ela mesma é relação. Mas não qualquer relação. A volubilidade de seu significado - indo dos estados patológicos da biomedicina

Antropológicos, 23(48), UFRGS (2017). Por outro lado, conta-se apenas um dossiê - Religião e Sociedade, 35(1), 2015 - dedicado a reunir artigos em torno da associação materialidade-sacralidade. 
e psiquiatria ao movimento transformativo - indica que ela oscila entre a instabilidade e o devir. Aristóteles (1969) já havia fixado tal altercação semântica:

\footnotetext{
"Afecção" significa (1) uma qualidade em relação à qual uma coisa pode ser alterada, como a brancura e a negridão, a doçura e o amargor, o peso e a leveza, e tudo mais da mesma espécie. (2) A atualização de tudo isso - em outras palavras, as alterações já efetivadas. (3) Especialmente, as alterações e movimentos nocivos e, acima de tudo, os ferimentos dolorosos. (4) "Afecções" também se diz dos grandes e calamitosos infortúnios" (Livro $V, 21,1022 b)$.
}

No artigo de Bruno Silva Santos, "Dó e alegria: relações entre os Guarani-Mbya e seus cães no Jaraguá/SP", as afeções são o liame fundamental entre índios e cães, explicando a adoção contínua desses animais como atualização cosmológica da relação mymbadono vivida pelos Guarani-Mbya em sua experiência com os deuses. Na Terra Indígena mais exígua do Brasil, encravada nos limites da maior cidade latino-americana, apresentando péssimas condições sanitárias e uma população canina quase igual à humana, os Guarani-Mbya, cães e deuses estão conectados por cuidados e proteção, afecções que os dispõem em relações do tipo domínio-maestria típicas do universo ameríndio. De tal modo que "Estar alegre - ou seja, partilhar da condição de humanidade - é tanto saber-se e fazer-se cuidado pelos deuses, quanto ser reconhecido pelos cães, e demais animais de estimação, como 'dono'".

A relação domínio-maestria é fundamental para a completude da pessoa Guarani que garante sua integridade com a proximidade dos cães, uma vez que estes, com sua visão, podem impedir que os espíritos angue tragam adoecimento e morte aos índios. Os cães protegem os Guarani porque por eles são protegidos.

Voltemos ao universo das coisas. A presença decisiva de "coisas", "artefatos" ou "objetos" entre nós tem sido retratada pela antropologia desde os tempos clássicos da disciplina, sendo que o principal motivo de seu interesse pela dimensão material da vida nativa reside mais no fato de artefatos poderem ser fortes mediadores de relações interhumanas e menos pelo acesso que nos proporcionam às teorias locais sobre ontologia e materialidade. Assim foi para os soulava e mwali, respectivamente colares e braceletes do circuito do Kula, motores precípuos de um "vasto encadeamento de relações intertribais numa grande instituição que incorpora milhares de pessoas, todas elas unidas 
por uma paixão comum pelas transações do Kula" (MALINOWSKI, 1984, p. 78). A exceção clássica fica por conta, talvez, de Mauss (2003) ao buscar no hau e mana ("espírito das coisas"), da Polinésia e Melanésia, a explicação para a força moral do darreceber-retribuir, esforço que, consoante Lévi-Strauss (2003), teria conduzido Mauss a buscar a origem do mana na "ordem de sentimentos, volições e crenças" (MAUSS, op. cit., p. 39), retornando ao velho paradigma durkheimiano das forças misteriosas que representariam emanações ocultas da sociedade.

Esse domínio das relações humanos-artefatos, para além das teorias sociológicas da mediação, parece ter ficado dormente para a antropologia, em especial para a antropologia da "cultura material" dos anos de 1970 e 1980. De resto, o despertar de tal sono dogmático deve-se tardiamente a Alfred Gell (1998), introduzindo o estatuto de pessoa na obra de arte e, em consequência, focando sua dimensão agentiva.

Não obstante a preocupação de Gell em redesenhar uma antropologia da arte e não em escrever teorias nativas sobre arte, sua contribuição para uma reflexão acerca da agência de artefatos em geral foi sentida pelas etnologias sul-americana, melanesiana e alhures, atentas às teorias locais da materialidade. Nesse sentido, duas obras de referência surgiram nos últimos dez anos. Em Henare et al. (2007) o esforço está em produzir etnografias sobre a materialidade em lugares díspares como Nova Guiné, Cuba, Nova Zelândia e Mongólia, assumindo a necessidade premente de propor/executar metodologias alternativas que possibilitem alcançar, etnograficamente, as teorias nativas sobre materialidade, desviando-se dos fragmentos de modelos presentes na orbita da compreensão antropológica. Já em Santos-Granero (2009) - coletânea que reúne exclusivamente etnografias amazônicas - o alvo não é apenas lançar luz sobre teorias ameríndias da materialidade em particular, mas, no conjunto, realçar a posição de coisas em geral (e em particular artefatos) nas cosmologias amazônicas. Santos-Granero (2009) indica que o predomínio de temas como economia política e relação com o animal (especialmente a caça) nos estudos etnológicos sobre a região vêm secundarizando a importância de artefatos e coisas para os povos amazônicos. Por sua vez, a noção de cultura material mostrou-se inapropriada para tratar do tema da materialidade na 
Amazônia, uma vez que obscurece o fato de, nas cosmologias aí presentes, artefatos (e coisas) serem potencialmente subjetividades partícipes da vida social.

Tanto o animismo de Descola $(1992 ; 1996)$ quanto o perspectivismo de Eduardo Viveiros de Castro (2003) teriam falhado ao não refletirem sobre o estatuto ontológico dos artefatos na região. O perspectivismo - que considera animais, humanos e espíritos como as três categorias fundamentais de seres vivos nas cosmologias amazônicas - vê artefatos como secundariamente espiritualizados, às vezes como derivação da espiritualização de animais (VIVEIROS DE CASTRO, op. cit. p. 2). "Coisas" - a exemplo de artefatos, canções, grafismos, nomes, fenômenos meteorológicos, etc. - não são, como mostra Santos-Granero (2009), derivativos, mas centrais nas cosmologias construcionistas amazônicas.

Não obstante o consenso em torno da importância dos artefatos no conjunto das socialidades interespecíficas ameríndias e alhures, no domínio dos estudos sobre teorias locais da materialidade devemos pensar em frentes relativamente autônomas entre si que funcionam como sendas distintas dentro de uma floresta, algumas mais circulares, outras menos. Mas duas questões se colocam a todas elas: primeiro, até que ponto as "coisas" são feitas ou "crescem", "emergem", em uma teia de relações com outros entes, incluindo nós, humanos? E se coisas emergem e crescem, qual o verdadeiro sentido da distinção entre coisas (entes) "animadas" e "inanimadas"?

Buscar respostas criativas a tais questões tem sido o esforço de Tim Ingold ao propor a percepção da "natureza" (environment) como enredamento ou entrelaçamento (entang/ement), imagens que corresponderiam a uma malha complexa de relações onde estão todos os entes e que foi sintetizada por lan Hodder (2012) por meio da seguinte fórmula: entanglement = dependência humano-coisa + dependência coisa-coisa + dependência coisa-humano + dependência humano-humano.

Todos os entes, portanto, em níveis diferentes, teriam agência (e talvez intencionalidade), uma vez que estão densamente relacionados entre si. Ingold (2011) afirma que é preciso considerar seriamente que as pessoas nem sempre pensam "animado" e "inanimado" como domínios antitéticos, uma vez que a "vida" não pode ser identificada como uma 
qualidade restrita a alguns entes. Como demonstram coletivos tradicionais que compartilham daquilo que ele chama de ontologia anímica, a qualidade de animado (animacy) depende da relação entre os entes no mundo, não é uma propriedade particular de nenhum deles. Assim, trata-se antes de "... um potencial dinâmico, transformativo do campo total de relações em que seres de todos os tipos, mais ou menos como pessoas ou como coisas, continua e reciprocamente se fazem existir" (INGOLD, op. cit., p. 68). Na ontologia anímica a vida é uma geração contínua: abertura dos entes a um mundo-em-devir. A relação com o mundo não se dá como representação de coisas finitas e completas, mas é um nascimento contínuo. Consoante Merleau-Ponty, as "coisas" estão sempre se tornando "coisas" e o mundo está sempre se tornando mundo. Ingold, bastante influenciado pela fenomenologia, concebe o organismo como uma malha (meshwork) de linhas ramificadas projetadas como seus rastros e pistas de açõesno-mundo, à imagem inversa do autocontido. $\mathrm{O}$ meio ambiente enquanto entrelaçamento (entanglement) não é um espaço que contém organismos ou coisas, uma vez que não há fronteiras entre o ente e o mundo, mas apenas traços, trilhas e pistas de movimento e crescimento que são linhas de relação "ao longo das quais a vida é vivida" (INGOLD, op. cit., p. 69). Tal emaranhado compõe a textura do mundo vivo e é nesse campo relacional - constituído à imagem de uma malha (entrelaçado de linhas) em oposição a uma rede (pontos interconectados) - que os organismos são constituídos.

\section{Novas associações}

Socialidades podem ser pensadas como interespecíficas, não por conectarem entidades previamente distintas (ou espécies lineanas), mas por se configurarem como o próprio espaço em que as relações são estabelecidas e, ao mesmo tempo, ou por isso mesmo, onde se desenrola o viver, a cada momento. Nem o devir (ou uma ecologia) das coisas, nem dos organismos (ou a tessitura de suas relações), parece sensibilizar as ciências linguísticas, um ramo do conhecimento comprometido com as "humanidades" ao assumir que seu objeto de estudo - a linguagem - é propriedade específica de uma espécie. É o que sugere Beto Vianna em seu “Escutar (o) não humano: mais coisas entre 
o céu e a terra do que sonham nossos signos linguísticos", propondo um isomorfismo entre os domínios linguístico ("domínio comportamental de ações coordenadas e consensuais") e social (biologicamente ativado) no que concerne à modulação das ontogenias a partir do histórico de interações dos organismos, sendo possível transcender a linguagem como um afazer meramente humano, para observá-la em toda relação coontogênica (ou seja, entre "sistemas em desenvolvimento" ${ }^{8}$ ). Esse modo de pensar a interação entre organismos em contínua mudança estrutural (entre sistemas ontogênicos) é inspirada nos trabalhos da escola chilena conhecida como Biologia do Conhecer (MATURANA, 1997), que define assim o sistema vivo:

... una máquina organizada como un sistema de procesos de producción de componentes concatenados de tal manera que producen componentes que: (i) generan los procesos (relaciones) de producción que los producen a través de sus contínuas interacciones y transformaciones, y (ii) constituyen a la máquina como una unidad en el espacio físico. (MATURANA; VARELA, 2003, p. 69).

Tais processos de conservação do vivo foram denominadas autopoiese (MATURANA; VARELA, op. cit., p. 69), em referência à autoprodução das redes moleculares no nível celular. Em suas associações de segunda (sistemas multicelulares) e terceira ordens (associações entre organismos, ou sistemas sociais) as redes autopoiéticas são tão interespecíficas quanto as macroredes vigentes entre humanos e animais ou humanos e artefatos, ainda que na Biologia do Conhecer o fundamento dos processos associativos seja biológico. Seu resultado, no entanto, não se alimenta das categorias "vivo" e "inanimado", mas são fenômenos necessariamente relacionais a que usualmente chamamos de cognição e linguagem: respectivamente, um agir sobre o mundo e um dizer $o$ mundo que dependem das associações entre o organismo e si mesmo (a fisiologia) e com o entorno, que pode incluir outros organismos (relações coontogênicas).

Associações criadas não apenas com o entorno, mas em torno das redes interespecíficas, são exploradas por Andrea Barbosa Osório em seu "Dádiva e antiprofissionalização na

8 OYAMA, 2000. 
proteção a animais de rua". Osório implica a economia da dádiva (MAUSS, 2003), e suas relações com a economia capitalista, ou de mercado, no operar das redes de proteção de animais. Derivando a condição de vulnerabilidade de certos organismos a partir de sua associação com humanos, os protetores entendem que seus coespecíficos "têm a obrigação moral de acudir animais de rua" e, ao coletar e doar os animais, estes são transformados, de objetos-mercadoria - comprados, vendidos e descartados -, em pessoas, porquanto inseridas em uma rede de relações afetivas interespecíficas. Por outro lado, o próprio transitar entre não-pessoa e pessoa, e, ainda, as estratégias de financiamento das redes de proteção, apontam para interpenetrações entre a economia do dom e os modos de produção/distribuição capitalistas, em que "dádivas e mercadorias podem incorporar as características uma da outra e confundir suas identidades". Em todo caso, a macrorrede que envolve o animal de rua e suas malhas protetoras transcende sua própria interespecificidade. Transpondo a questão da produção de excedentes em economias da dádiva para o "excesso" de animais nas ruas, a autora aponta que, sua contenção,

... tem sido buscada por atores eivados de ideologias distintas, que perpassam tanto os próprios protetores e sua ideologia de posse responsável, que visa contê-los da reprodução à mobilidade (...), quanto de biólogos e ecologistas, preocupados com as consequências de suas ações na fauna local.

Pensar a transição de não-pessoa a pessoa (tanto nas efetivas relações que estabelecemos, quanto nas mudanças de paradigma) e pensar as associações entre humanos e não humanos (também no viver cotidiano e nos relatos acadêmicos), nos lembra como estamos imersos em uma cultura que opõe radicalmente o que é da natureza e com quem (nós, humanos) podemos (oficialmente) socializar. Inspirados nesse recorte dicotômico fundamental, aprendemos a separar também o selvagem e o doméstico, que supõe a anterioridade da primeira condição (a matéria "bruta", o animal livre, a criança pré-linguística, os povos paleolíticos) e a domesticação como passagem (de preferência, irreversível) para o domínio da cultura: uma antropogênese tanto do animal, quanto do humano, sem nos esquecermos de outras materialidades igualmente domesticadas (dos artefatos mais corriqueiros às barragens hidrelétricas). 
Em "Do lobo e do humano: um olhar antropológico sobre a relação homem-animal em duas obras de Jack London", Hugo de Carvalho Ferreira explora duas histórias animadas por seus respectivos protagonistas caninos: um cão doméstico que termina por viver na companhia dos lobos, e um lobo-cão selvagem que termina por viver em companhia dos humanos. A partir do duplo devir que essas obras sinalizam, o artigo põe em questão a cisão ontológica entre o selvagem e o doméstico, só permeáveis, e em via de mão única, pela ação exclusiva do humano sobre entes pretensamente originários ${ }^{9}$. Que isso não é necessariamente assim, atestam as muitas etnografias dos povos ameríndios, como o relato sobre os xerimbabos, os animais familiarizados no convívio dos Matis. Para estes, diz o autor, "a domesticidade é um processo, o qual requer trabalho e esforço, estando por isso em constante ameaça". Ferreira nos conta que as obras de Jack London foram criticadas em sua época (início do século XX), por propor, para seus personagens animais, comportamentos antinaturais, em geral antropomórficos, mas também contrários a um "instinto", um conceito persistente em nossa cultura científica. Isso nos leva ao corte cartesiano mente/máquina fundacional na matriz epistemológica moderna, em particular na etologia (ciência do comportamento animal), mas dominante nas mais diversas disciplinas acadêmicas, principalmente as que se filiam às ciências cognitivas, como as neurociências, a linguística, a antropologia, e as psicologias de vários matizes. Vale a pena citar dois trechos do antropólogo/psicólogo Gregory Bateson (2000, p. 3840) em um de seus geniais "metálogos", que encenam conversas com a filha:

Filha: Papai, o que é instinto?

Pai: Instinto, querida, é um princípio explicativo.

F: Mas o que ele explica?

P: Qualquer coisa - quase tudo. Qualquer coisa que você quiser que ele explique.

F: Não seja bobo. Ele não explica a gravidade.

P: Não. Mas isso é porque ninguém quer que "instinto" explique a gravidade.

Se quisessem, ele explicaria. Poderíamos simplesmente dizer que a lua tem

um instinto cuja força varia inversamente ao quadrado da distância...

(...)

F: Papai, o que é um instinto?

P: É uma etiqueta para o que uma certa caixa-preta supostamente faz.

\footnotetext{
${ }^{9}$ Crianças selvagens (criadas longe do convívio humano; ver Candland, 1993) e animais assilvestrados (de origem doméstica) são considerados anomalias, no sentido de "contrário ao normal" (ainda que os últimos sejam bastante comuns mundo afora),reafirmando a naturalização do natural em nossa cultura.
} 


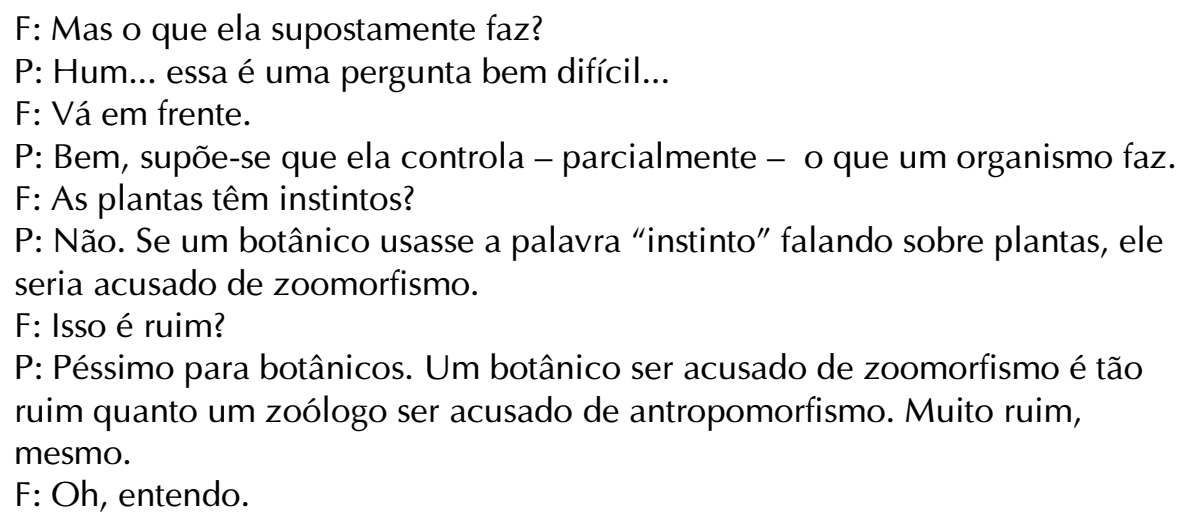

Se podemos usar "domesticado" em outro sentido e contexto (sem dúvida derivados do primeiro, talvez com maior apelo crítico), a tarefa que os estudos animais e das agências não humanas, em suma, das socialidades interpecíficas, têm pela frente, é formidável, graças ao apreço de nossa cultura acadêmica e científica por cisões ontológicas tão empobrecedoras quanto persistentes. O que se debate, portanto, é a nossa própria domesticação. Caminhos explicativos diversos existem, e nos artigos que compõem este dossiê, em um nível ou em outro, é a relação que vai particularizar os termos relacionados, definindo a anterioridade da diferença sobre a identidade, da forma sobre o conteúdo e da estrutura sobre o processo. Sem deixar de considerarmos os afastamentos e idiossincrasias, podemos dizer que todos os artigos aqui publicados, assim como as abordagens que os inspiram, são relacionistas, isto é, compartilham do consenso de que a relação antecede os entes relacionados (ao menos em versão particularizada), paradigma que transita do estruturalismo à fenomenologia, do pensamento sistêmico às socialidades simétricas, devidamente revisitados pelos cinco autores. 


\section{Referências}

ARISTÓTELES. Metafísica. Porto Alegre: Editora Globo. 1969.

BATESON, Gregory. What is an instinct? In: BATESON, Gregory. Steps to an ecology of mind. Chicago: Chicago University Press, p. 38-58, 2000.

BRADY, Heather. "Paul McCartney wants you to do one thing for the planet". Disponível em: $\quad$ https://news.nationalgeographic.com/2017/11/paul-mccartney-documentarybeatles-vegetarian-meat-mondays/. Publicado em 01/11/2107. Acessado em 30 de novembro de 2017.

CANDLAND, Douglas Keith. Feral children and clever animals: reflections on human nature. Oxford: Oxford University Press, 1993.

DAWKINS, Richard. O relojoeiro cego: a teoria da evolução contra o desígnio divino. São Paulo: Cia das Letras, 2001.

DESCOLA, Philippe. "Societies of nature and the nature of society". In: Adam Kuper (Ed.) Conceptualizing society. London \& New York: Routledge, p. 107-126. 1992.

DESCOLA, Philippe. "Constructing natures: symbolic ecology and social practice". In: DESCOLA, Philippe; PÁLSSON, Gísli (Eds.). Nature and Society: anthropological perspectives. London \& New York: Routledge, p. 82-102. 1996.

DE WAAL, Frans. The ape and the sushi master: cultural reflections of a primatologist. New York: Basic Books, 2001.

FRAZER, James G. "O escopo da antropologia social". In: CASTRO, Celso (Org.). Evolucionismo cultural. Rio de Janeiro: Jorge Zahar, p. 101-127. 2005.

GELL, Alfred. Art and agency: an anthropological theory. Oxford: Clarendon. 1998. HAMLYN, D. W. Metaphysics. Cambridge: Cambridge University Press. 1984.

HENARE, Amiria et al. (eds.). Thinking through things: theorising artefacts ethnographically. London \& New York: Routledge. 2007.

HODDER, lan. Entangled: an archaelogy of the relationships between humans and things. London: Wiley-Blackwell. 2012. 
INGOLD, Tim. Being alive: essays on movement, knowledge and description. London: Routledge. 2011.

KALOF, Linda; FITZGERALD, Amy (Eds.). The animals reader: the essential classics and contemporary writings. Oxford: Berg, 2007.

LATOUR, Bruno. Jamais fomos modernos: ensaio de antropologia simétrica. Rio de Janeiro: Editora 34. 1994.

LÉVI-STRAUSS, Claude. "Introdução à obra de Marcel Mauss". In: MAUSS, Marcel. Sociologia e antropologia. São Paulo: Cosac \& Naify, p. 11-46, 2003.

MATURANA, Humberto. Tudo é dito por um observador. In: MAGRO, Cristina; GRACIANO, Miriam; VAZ, Nelson (Orgs.). A ontologia da realidade. Belo Horizonte: Editora UFMG, 1997. p. 53-76.

MATURANA, Humberto; VARELA, Francisco. De máquinas y seres vivos. Buenos Aires: Lumen, 2003.

MAUSS, Marcel. "Ensaio sobre a dádiva: forma e razão da troca nas sociedades arcaicas". In: Sociologia e antropologia. São Paulo: Cosac \& Naify, p. 183-314, 2003. OYAMA, Susan. The ontogeny of information: Developmental systems and evolution. Durham: Duke University Press, 2000.

RORTY, Richard. A filosofia e o espelho da natureza. Rio de Janeiro: Relume Dumará, 1994.

SANTOS-GRANERO, Fernando. "Introduction: Amerindian constructional views of the world". In: SANTOS-GRANERO, Fernando (Ed.). The occult life of things: native Amazonian theories of materiality and personhood. Tucson: The University of Arizona Press, p. 1-29, 2009.

STRATHERN, Marilyn. The concept of society is theoretically obsolete - For the motion (1). In: INGOLD, Tim (Ed.) Key debates in anthropology. London/New York: Routledge, p. 50-55, 1998.

STENGERS, Isabelle. Cosmopolitics I. Minneapolis: University of Minesota Press, 2010. 
VIVEIROS DE CASTRO, Eduardo. A inconstância da alma selvagem e outros ensaios de antropologia. São Paulo: Cosac \& Naify, 2002.

WAGNER, Roy. Are there social groups in the New Guinea highlands? In: LEAF, Murray (Ed.). Frontiers of anthropology. Nova York: Cincinnati/Toronto, London, Melbourne: D. Van Nostrand Company, p. 95-122, 1974.

WAGNER, Roy. The invention of culture. Chicago/London: The University of Chicago Press, 1981.

WATSON, Lyall. The nature of things: the secret life of inanimate objects. London: Hodder \& Stoughton, 1990.

STEFFEN, Will; GRINEVALD, Jacques; CRUTZEN, Paul; MCNEILL, John. The Anthropocene: conceptual and historical perspectives. Phil. Trans. R. Soc. A, 369, 842867, 2011. 